\title{
Calibrators for Clinical Measurements of Phosphorylated H2AX in Patient Cells by Flow Cytometry
}

\author{
Aida Muslimovic, Pegah Johansson, Ulla Ruetschi and Ola Hammarsten* \\ Department of Clinical Chemistry and Transfusion Medicine, Sahlgrenska University Hospital, Gothenburg University, \\ SE-413 45 Göteborg, Sweden
}

\begin{abstract}
Agents that induce DNA double-strand breaks (DSBs), such as ionizing radiation, are frequently used in cancer therapy. H2AX is rapidly phosphorylated in response to DSBs and serves as a way to measure the extent of DSBs induced in patient cells. We have previously reported a flow cytometry-based method for measuring $\mathrm{H} 2 \mathrm{AX}$ phosphorylation in patient cells undergoing radiotherapy. To be able to implement measurement of H2AX phosphorylation in clinical practice, we have characterized calibrators for the flow cytometry analysis based on phosphopeptide-coated beads and fixed cells. The calibrator beads and fixed cells lost less than $11 \%$ of the signal after storage for 40 days under optimal conditions and were able to correct for day-to-day variation in method performance.
\end{abstract}

Keywords: Calibrators, internal controls, correction, variation, flow cytometry, gamma-H2AX, P-H2AX.

\section{INTRODUCTION}

Induction of DNA double-strand breaks (DSBs) by IR or chemotherapy is responsible for the treatment effect in cancer therapy [1]. One of the first cellular responses to DSBs is phosphorylation of the histone $\mathrm{H} 2 \mathrm{AX}$ [2]. H2AX is a variant of histone $\mathrm{H} 2 \mathrm{~A}$ containing a distinct C-terminal extension with a consensus phosphorylation site that becomes phosphorylated in a DSB-specific manner. Surrounding the DSB, thousands of $\mathrm{H} 2 \mathrm{AX}$ molecules become phosphorylated by the aid of several DSB-activated protein kinases including ATM, ATR and DNA-PK, leading to the formation of nuclear structures called gamma-H2AX (denoted $\mathrm{P}-\mathrm{H} 2 \mathrm{AX}$ in this paper) foci within minutes of DSB induction [3-8]. After staining with fluorescence-labeled antibodies against P$\mathrm{H} 2 \mathrm{AX}$, it is possible to count distinct $\mathrm{P}-\mathrm{H} 2 \mathrm{AX}$ foci in cell nuclei, which most likely represent single DSBs [9-11]. P$\mathrm{H} 2 \mathrm{AX}$ can also be measured by flow cytometry [12-16] and several reports indicate that measurements of the H2AX response could be used to monitor the number of DSBs induced by radiation and chemotherapy and that this could be a way to personalize the dosing of DNA-damaging drugs and radiation.

To be able to use the flow cytometry-based P-H2AX method in clinical routine practice and to relate the extent of $\mathrm{P}-\mathrm{H} 2 \mathrm{AX}$ signal to the clinical outcome and side effects, calibrators that can be used to monitor bias and precision of flow cytometry-based P-H2AX method are required.

Here, we characterize two different calibrators based on phosphopeptide coated plastic beads or fixed cells.

\footnotetext{
*Address correspondence to this author at the Department of Clinical Chemistry and Transfusion Medicine Bruna stråket 16, Sahlgrenska Academy at the University of Gothenburg, SE-41345 Gothenburg Sweden; Tel: 0046313421561; Fax: 004631828458;

E-mail: ola.hammarsten@clinchem.gu.se
}

\section{MATERIAL AND METHODS}

\section{Cells and Reagents}

Calicheamicin $\gamma 1$ (CLM) was a generous gift from George Ellestad (Wyeth-Ayers Research). CLM was dissolved at $2 \mathrm{mM}$ in DMSO and stored at $-70^{\circ} \mathrm{C}$. Primary fibroblasts were cultured in MEM (SIGMA) supplemented with $10 \%$ fetal bovine serum, 1X MEM Non-essential Amino Acid Solution (100×) (SIGMA), 1X sodium pyruvate (100mM, 100X) (SIGMA), penicillin and streptomycin. Cells were grown in a humidified atmosphere with $5 \% \mathrm{CO} 2$.

\section{Mass Spectrometry Analysis}

H2AX phosphopeptide with the sequence CKATQA $\{\mathrm{pSer}$ QEY and biotin on the $\mathrm{N}$ terminal, was purchased from Genscript. The peptide was diluted in $\mathrm{H}_{2} \mathrm{O}$ to $1 \mathrm{mg} / \mathrm{ml}$, aliquoted and stored at $-70^{\circ} \mathrm{C}$. Prior to matrix-assisted laser desorption time of flight (MALDI-TOF) mass spectrometry (MS), the peptides were desalted and enriched using ZipTip C18 pipette tips (Millipore). Ten microliters of peptide solution at a concentration of $1 \mathrm{mg} / \mathrm{mL}$ was applied to the ZipTip and bound peptides were extensively washed in $0.1 \%$ trifluoroacetic acid. Desalted peptides were eluted in $3 \mu \mathrm{l}$ MALDI matrix solution ( $10 \mathrm{~g} / \mathrm{L} \alpha$-cyano-4-cinnamic acid in $80 \%$ acetonitrile, $0.1 \%$ formic acid) directly onto the MALDI target (MTP AnchorChipTM 400/384 TF) and the solution was allowed to air-dry. MALDI-TOF MS measurements of positive ions were performed using an Autoflex instrument (Bruker Daltonics Inc.) operating in linear mode and the acquired spectra represent an average of 1000 singleshot measurements. The spectra were externally calibrated using a calibration equation obtained from measurements of the reference masses in the Peptide calibration standard II (Bruker Daltonics). To verify the phosphorylation state of 
the peptide, MALDI-TOF spectra were also acquired in the reflected mode.

\section{Preparation and Storage of Calibrator Beads}

For stability testing three different batches of phosphopeptide coated beads were prepared. Streptavidin-coated magnetic Dynabeads (Invitrogen) (2 000 000) diluted in PBS were mixed with $0.003,0.01$ and $0.04 \mathrm{ng}$ phosphopeptide per bead for $1 \mathrm{~h}$ at $21^{\circ} \mathrm{C}$. After incubation, the beads were separated with a DynaMag magnet (Invitrogen) and washed three times with $0.5 \mathrm{ml}$ PBS before suspension in $100 \mu \mathrm{l}$ PBS, $0.1 \mathrm{~g} / 1 \mathrm{BSA}$. The beads were then aliquoted to obtain 200000 beads per tube and dried in a vacuum centrifuge for $1 \mathrm{~h}$. Lastly, the tubes were flushed with $\mathrm{N}_{2}(\mathrm{~g})$ and stored at $21^{\circ} \mathrm{C}$ or $-70^{\circ} \mathrm{C}$. The beads were analyzed before and after drying on days 1, 4, 7, 11, 20 and 40. For the correction experiments phosphopeptide coated beads with $0.0025,0.005$, $0.01,0.015,0.025,0.08,0.1 \mathrm{ng} /$ bead were prepared in the same way. On the day of analysis, beads were resuspended in $50 \mu \mathrm{l} \mathrm{H}_{2} \mathrm{O}$ and analyzed according to the protocol described under the Flow Cytometry Analysis. As a control for day-to-day variation of the flow cytometer signal we correlated all FITC-signals from phosphopeptide coated beads analysed at different days with the FITC-signal obtained from FITC-labeled beads from the Calibrite beads kit (cat. nr. 349502, Becton, Dickinson and Company (BD)) that according to the insert are stable for up to 8 months.

\section{Preparation and Storage of Calibrator Cells}

To test optimal fixation protocol and storage conditions primary human fibroblasts $(300000)$ were treated with 0.5 $\mathrm{nM}$ CLM for $30 \mathrm{~min}$ at $37^{\circ} \mathrm{C}$. After treatment, the monolayers were washed with $1 \mathrm{ml}$ PBS and trypsinized. The cells were resuspended in $1 \mathrm{ml}$ of culture medium and centrifuged for $4 \mathrm{~min}$ at $4000 \mathrm{xg}$. The pellet was washed with $1 \mathrm{ml}$ icecold PBS and centrifuged for $4 \mathrm{~min}$ at $4000 \mathrm{xg}$. The cells were then either fixed in $0.5 \mathrm{ml}$ PBS, $2 \%$ PFA or not fixed for $30 \mathrm{~min}$ on ice. The fixed cells were washed with $1 \mathrm{ml}$ ice-cold PBS and diluted in $10 \mu \mathrm{l}$ PBS, after which both PFA-fixed and not fixed cells were fixed in a total volume of $100 \mu \mathrm{l}$ in $\mathrm{MetOH}$ or $\mathrm{EtOH}$ (final concentration $90 \%$ ) added while vortexing to prevent formation of aggregated cells. The fixed cells were aliquoted and stored at $-70^{\circ} \mathrm{C}$. At the same time aliquots of the Block-H staining solution (PBS, $1 \mathrm{~g} / 1 \mathrm{BSA}$ with $0.05 \% \mathrm{NaN}_{3}, 0.1 \mathrm{~g} / 1 \mathrm{RNase} A$, phosphatase inhibitors (10 mM NaF, $1 \mathrm{mM} \mathrm{Na} \mathrm{MoO}_{4}, 1 \mathrm{mM} \mathrm{NaVO}$ ), $0.25 \mathrm{~g} / 1$ herring sperm DNA, $0.1 \%$ Triton X-100, $5 \mathrm{mM}$ EDTA) and separate aliquots of the mouse monoclonal antiH2AXS139ph FITC conjugate (Millipore) were stored at $-70^{\circ} \mathrm{C}$. On the day of analysis $(3,10$ and 40 days after storage), the cells were centrifuged for $1 \mathrm{~min}$ at $13000 \mathrm{xg}$. $\mathrm{MetOH}$ and $\mathrm{EtOH}$ were gently pipetted off and the remains were allowed to evaporate. The pellet was suspended in 50 $\mu \mathrm{l}$ PBS, $1 \mathrm{~g} / \mathrm{l} \mathrm{BSA}$ and analyzed according to the protocol described under Flow Cytometry Analysis using a freshly thawn aliquot of Block-H and mouse monoclonal antiH2AXS139ph FITC conjugate (Millipore). As a control we used the FITC-labeled beads from the Calibrite beads kit to correct for instrument day-to-day variation (cat. nr. 349502, Becton, Dickinson and Company (BD)) that according to the insert are stable for up to 8 months. To test the influence of freezing on signal intensity we treated primary fibroblasts with $0,0.03$ and $0.3 \mathrm{nM}$ CLM for $30 \mathrm{~min}$, at $37^{\circ} \mathrm{C}$, fixed with $\mathrm{EtOH}$ and analyzed by flow cytometry on days 1 before and after freezing and on day 7. For the final correction experiments primary fibroblasts (ca. 9000 000) were treated with $0,0.03125,0.0625,0.125,0.25,0.5$ and $1 \mathrm{nM}$ CLM as described above. After the treatment, the monolayers were washed with $50 \mathrm{ml}$ PBS and trypsinized. The cells were resuspended in $10 \mathrm{ml}$ medium and centrifuged for $4 \mathrm{~min}$, $4000 x g$. The pellet was washed in $10 \mathrm{ml}$ ice-cold PBS and centrifuged for $4 \mathrm{~min}, 4000 \mathrm{xg}$ and fixed by addition of icecold EtOH while vortexing as described above. The fixed cells were aliquoted to obtain 250000 cells per tube and finally stored at $-70^{\circ} \mathrm{C}$. The high cell number was chosen to facilitate fast and convenient flow cytometry analysis; however, it is possible to use $12500-500000$ cells without any significant change of the signal with the antibody concentrations used (data not shown). On the day of analysis, the cells were analyzed by flow cytometry as described above.

\section{Flow Cytometry Analysis}

Suspensions $(50 \mu \mathrm{l})$ of the calibrator beads, calibrator cells or freshly treated fibroblasts were added to $150 \mu \mathrm{l}$ Block-H (PBS, $1 \mathrm{~g} / 1 \mathrm{BSA}$ with $0.05 \% \mathrm{NaN}_{3}, 0.1 \mathrm{~g} / \mathrm{l}$ RNaseA, phosphatase inhibitors $(10 \mathrm{mM}$ NaF, $1 \mathrm{mM}$ $\mathrm{Na}_{2} \mathrm{MoO}_{4}, 1 \mathrm{mM} \mathrm{NaVO}$ ), $0.25 \mathrm{~g} / 1$ herring sperm DNA, 0.1 $\%$ Triton X-100, 5 mM EDTA, 1:1000 mouse monoclonal anti-H2AXS139ph FITC conjugate (Millipore)) and stained for 3 hours at $4^{\circ} \mathrm{C}$. The samples were then diluted with $300 \mu \mathrm{l}$ suspension buffer (PBS, 1g/l BSA) and analyzed by flow cytometry using FACSScan (BD) and FACSAria (BD) using a $488 \mathrm{~nm}$ excitation laser and 530/30 emission filter. The fluorescence intensity in arbitrary units was plotted in histograms and the mean fluorescence intensity was calculated using Weasel version 2.3 software.

\section{Correction for Batch Variation in Antibody Signal}

To examine if calibrator beads and cells could be used to correct for antibody related variations in the P-H2AX signal, we stained calibrator beads and calibrator cells fixed in $\mathrm{EtOH}$ in parallel with freshly treated fibroblasts with three different antibody batches and calculated correction factors that we used to correct for $\mathrm{P}-\mathrm{H} 2 \mathrm{AX}$ signal variations. Two different antibody batches with $70 \%$ and $50 \%$ of its original in fluorescence intensity were prepared by photo bleaching mouse monoclonal anti-H2AXS139ph FITC conjugate (Millipore) with a blue $(488 \mathrm{~nm})$ laser for $30 \mathrm{sec}$ and $2 \mathrm{~min}$, respectively. Confluent 6-well monolayers of primary fibroblasts were treated with $0,0.03,0.1,0.3 \mathrm{nM}$ CLM for $30 \mathrm{~min}$, at $37^{\circ} \mathrm{C}$. After the treatment, the monolayers were washed with $1 \mathrm{ml}$ PBS and trypsinized. The cells were resuspended in $1 \mathrm{ml}$ of medium and centrifuged for $4 \mathrm{~min}, 4000 \mathrm{xg}$. The pellet was washed with $1 \mathrm{ml}$ ice-cold PBS and centrifuged for $4 \mathrm{~min}, 4000 \mathrm{xg}$ after which it was diluted in $50 \mu \mathrm{l} \mathrm{PBS}$, $1 \mathrm{~g} / 1 \mathrm{BSA}$ and stained with the unbleached $(100 \%$ fluorescence intensity) and the photobleached antibody batches with $70 \%$ or $50 \%$ of the original fluorescence intensity and analyzed by flow cytometry together with calibrator beads and calibrator cells. The mean fluorescence intensity from calibrators stained with unbleached and photobleached antibody batches was used to calculate correction factors that were used to correct the fluorescence intensity from samples stained with photobleached antibodies closer to samples stained with the unbleached antibody. The correction factors generated from calibrator cells varied slightly with the fluo- 
rescence signal and therefore correction factors were chosen based on the level of the fluorescence signal in each sample.

\section{Corrections for day-to-day Variations}

EDTA blood from three healthy individuals was collected and irradiated in petri dishes with 1 and 5 Gy (Phillips RT 100 X-ray machine with acceleration voltage of $100 \mathrm{kV}$ ) on ice. The irradiated blood was incubated for $30 \mathrm{~min}$ in a $37^{\circ} \mathrm{C}$ water bath to induce $\mathrm{H} 2 \mathrm{AX}$ phosphorylation. Mononuclear cells were prepared by lympho-prep following instructions provided by the manufacturer (Alexis-Shield). Mononuclear cells from the three individuals, calibrator beads and calibrator cells fixed in EtOH were then analyzed with the PH2AX flow cytometry method. The same procedure was performed on the same individuals three days later. The mean fluorescence intensity from calibrator cells analyzed on day 1 and day 3 generated correction factors that were used to correct the fluorescence intensity from samples analyzed on day 3. The correction factor varied with the P-H2AX level. Therefore, the correction factor generated from calibrator cells close to the signal in each individual sample was used to correct the fluorescence signal between day 1 and 3, data shown in Fig. (4).

\section{RESULTS}

\section{Preparation and Characterization of Calibrator Beads}

To generate beads capable of binding the FITC-labeled monoclonal P-H2AX antibody used in the flow cytometry PH2AX method, we mixed streptavidin-coated paramagnetic beads with a biotinylated phosphopeptide derived from H2AX. We titrated the amount of peptide per bead to generate the optimal signal that matched the signal obtained in irradiated cells (Fig. 1A). To establish optimal storage conditions for the peptide-coated beads we first used mass spectrometry (MS) to analyze the stability of the phosphopeptide under different storage conditions (Table 1). The MS spectra indicated that some conditions generated a peptide signal with lower mass that failed to generate antibody-interacting beads (Fig. 1C). The mass difference between the intact (Fig 1B) and degraded peptide (Fig. 1C) matched the expected loss of the biotin moiety from the peptide. Based on the MS analysis the peptide was stable for 40 days when stored in $100 \%$ ethanol or phosphate buffer (Table 1). To assess the stability of the calibrator beads we analyzed FITC-labeled plastic beads (Calibrite beads (BD)) in parallel with calibrator beads as a control for variations in flow cytometer detector variations. When the calibrator beads were stored at

A

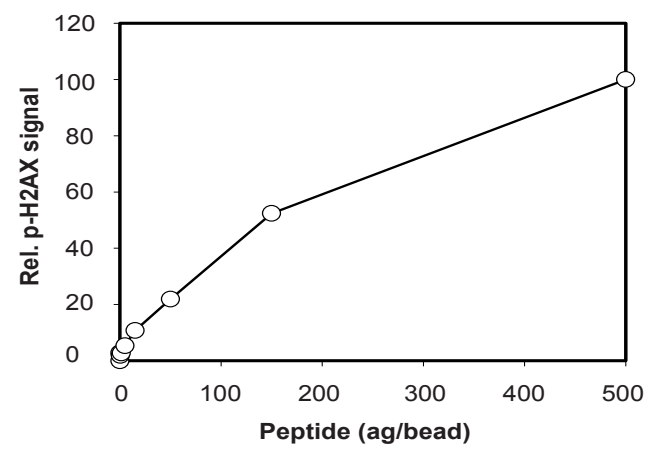

B

C
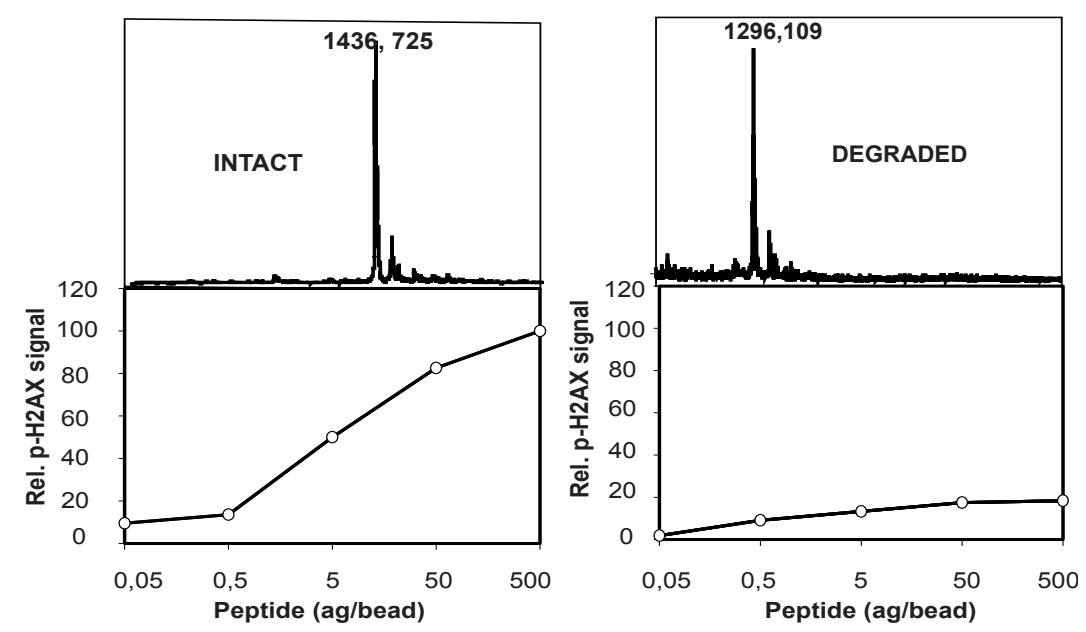

Fig. (1). Mass spectrometry and flow cytometry analysis of P-H2AX phosphopeptides. A: Phosphopeptide titration. Different amounts of biotinylated phosphopeptide were bound to streptavidin beads and the resulting beads were analyzed using the P-H2AX how cytometry method. B: Analysis of phosphopeptide stability. The P-H2AX-derived phosphopeptide was stored in $\mathrm{H}_{2} \mathrm{O}$ at $-70^{\circ}$ for 8 months and then analyzed by MS (upper plot). The same peptide preparation was bound to streptavidin beads and the resulting beads analyzed by the flow cytometry P-H2AX method (lower plot). C: Similar to B, but the peptide was stored in $10 \mathrm{mM} \mathrm{Na}_{2} \mathrm{PO}_{4} \mathrm{pH} 9.3+\mathrm{N}_{2}$ at $-70^{\circ}$ for 8 months. ag/bead: attogram/bead. 
Table 1. Stability of the Phospho-peptide

\begin{tabular}{|c|c|c|c|c|c|c|c|}
\hline \multirow{2}{*}{$\begin{array}{l}\text { Temperature } \\
\text { Storage Time }\end{array}$} & & \multicolumn{2}{|c|}{$21^{\circ} \mathrm{C}$} & \multicolumn{2}{|c|}{$-20^{\circ} \mathrm{C}$} & \multicolumn{2}{|c|}{$-70^{\circ} \mathrm{C}$} \\
\hline & & 10 days & 40 days & 10 days & 40 days & 10 days & 40 days \\
\hline & $10 \mathrm{mM} \mathrm{Na}_{2} \mathrm{PO}_{4} \mathrm{pH} 9.3$ & Intact & Degraded & Intact & Intact & Intact & Degraded \\
\hline Storage conditions & 10 mM Tris- $\mathrm{HCl} \mathrm{pH} 8.5$ & Degraded & Degraded & Intact & Intact & Intact & Intact \\
\hline & $10 \mathrm{mM} \mathrm{Na}_{2} \mathrm{PO}_{4} \mathrm{pH} 9.3+\mathrm{N}_{2}$ & Intact & Intact & Intact & Intact & Intact & Intact \\
\hline
\end{tabular}

$-70^{\circ} \mathrm{C}$, that according to the MS analysis generated optimal peptide stability, we found that calibrator beads lost $11 \%$ of the signal after 40 days (Table 2).

\section{Preparation and Characterization of Calibrator Cells}

Primary fibroblasts were treated with different concentrations of the DSB-inducing agent calicheamicin (CLM) and fixed to produce cells with a wide range of P-H2AX signals (Fig. 2A). The cells were then stored at different conditions for up to 40 days and analyzed by the P-H2AX Performance method (Table 3). FITC-labeled plastic beads (Calibrite beads (BD)) were analyzed in parallel with calibrator cells and used as a control for variations in flow cytometer detector variations. Storage of the fixed cells at room temperature or at $-70^{\circ} \mathrm{C}$ in different buffers without fixatives resulted in substantial loss of the P-H2AX signal and was not pursued further (data not shown). However, when CLM-treated and methanol or ethanol-fixed cells were stored at $-70^{\circ} \mathrm{C}$ in methanol or ethanol there was no significant loss of the P$\mathrm{H} 2 \mathrm{AX}$ signal after 40 days (Table 3 ). In addition, the freezing procedure did not affect the $\mathrm{P}-\mathrm{H} 2 \mathrm{AX}$ fluorescence signal (Fig 2B). The use of PFA in the fixation protocol lowered the P-H2AX signal, as reported before [12], and did not improve the stability of the P-H2AX signal (Table 3 ).

\section{Corrections of Antibody-related Differences in the P-H2AX Signal}

To test if the controls beads or EtOH-fixed calibrator cells could correct for differences due to batch differences in $\mathrm{P}-\mathrm{H} 2 \mathrm{AX}$ antibodies with different FITC intensities we used photobleaching to generate variable FITC intensities of the $\mathrm{P}-\mathrm{H} 2 \mathrm{AX}$ antibodies. The untreated and the photobleached batches of antibodies were then used to measure the $\mathrm{P}-\mathrm{H} 2 \mathrm{AX}$ signal in CLM-treated fibroblasts and in calibrator beads and calibrator cells. By using the signal from the calibrators we were able to correct the signal using the photobleached antibodies to match more closely the signal from the unbleached P-H2AX antibody (Fig. 3). There was no consistent difference in the ability to correct the signal using calibrator cells (Fig. 3A) or calibrator beads (Fig. 3B).

\section{Correction of Day-to-day Variation in Signal Intensity}

To test the ability of the EtOH-fixed cells to correct for day-to-day variations in signal intensity, mononuclear cells from three healthy individuals were irradiated in vitro and the resulting $\mathrm{P}-\mathrm{H} 2 \mathrm{AX}$ signal was analyzed. The procedure
A

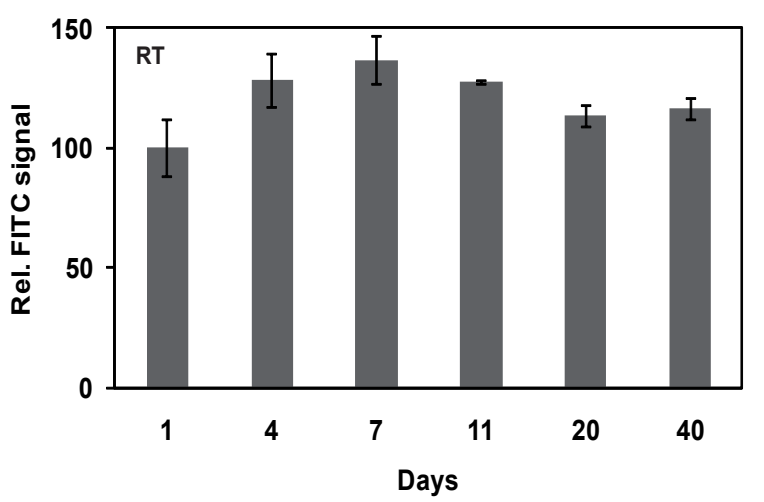

B

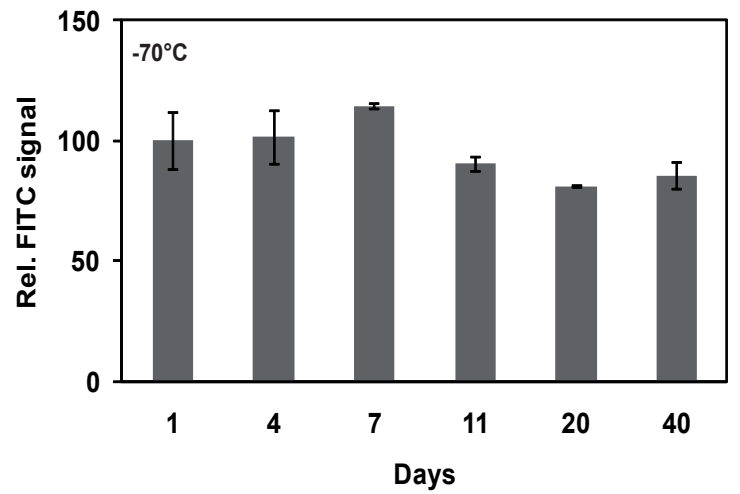

Fig. (2). Preparation and stability testing of calibrator cells. A: Determination of the dose relationship between the CLM concentration and the P-H2AX signal in human primary fibroblasts. Primary human fibroblasts were treated with $0,0.03,0.06,0.13,0.25$, $0.5,1$ and $3 \mathrm{nM}$ of CLM for $30 \mathrm{~min}$ at $37^{\circ} \mathrm{C}$, fixed in $90 \% \mathrm{EtOH}$, before analysis by flow cytometry. B: Storage effect on the P-H2AX signal in calibrator cells. Primary human fibroblasts were treated with $0,0.03$ and $0.3 \mathrm{nM}$ of CLM, (concentrations shown to be in the linear range from data in A) for $30 \mathrm{~min}$ at $37^{\circ} \mathrm{C}$ and fixed in $90 \% \mathrm{EtOH}$. Flow cytometry analysis was performed before freezing and after $1 \mathrm{~h}$ and 7 days of storage of the cells in $90 \%$ ethanol at $-70^{\circ} \mathrm{C}$. 
Table 2. Stability of Calibrator Beads

\begin{tabular}{|c|c|c|}
\hline Storage (days) & $\mathbf{2 1}^{\circ} \mathbf{C}$ (\% of Calibrite signal) & $\mathbf{- 7 0}^{\circ} \mathbf{C}$ (\% of Calibrite signal) \\
\hline \hline $1^{*}$ & $109(+/-4.0)$ & $109(+/-4.0)$ \\
\hline $1 * *$ & $114(+/-3.8)$ & $114(+/-3.8)$ \\
\hline 4 & $110(+/-3.4)$ & $121(+/-1.0)$ \\
\hline 7 & $114(+/-0.3)$ & $94(+/-0.1)$ \\
\hline 11 & $96(+/-1.5)$ & $87(+/-2.0)$ \\
\hline 20 & $95(+/-1.4)$ & $98(+/-0.1)$ \\
\hline 40 & $90(+/-4.7)$ & \\
\hline
\end{tabular}

*Before vacuum-drying **After vacuum-drying and freezing

was repeated two days later. At the same time, calibrator cells were analyzed on both days. The difference in the PH2AX signal from the calibrator cells obtained on day 1 and 3 were used to generate a range of signal strength-dependent correction factors for the day-to-day variation (Fig 4A). When the signal strength-adjusted correction factors were used, the day-to-day variation in the P-H2AX signal in these individuals was small and the corrected values showed less day-to-day variation compared with the uncorrected values (Fig. 4B, C and D).

\section{DISCUSSION}

Measurement of H2AX phosphorylation in patient cells have been discussed as a possible way to follow induction of DSBs after radiotherapy or chemotherapy, since this approach could be used to personalize the treatment. We have previously reported a flow cytometry method that can be used to measure the P-H2AX signal in patient cells during radiotherapy [13]. In order to apply this method in clinical routine practice, proper calibrators that can be used to correct for variation in the analytical procedure are required. In this paper we present two control materials based on phosphopeptide-coated beads (calibrator beads) and fixed cells with defined P-H2AX signals (calibrator cells). These two types of calibrators have their own merits.

The calibrator beads are easy to manufacture in large quantities in a standardized way and could help to minimize inter-laboratory differences. The calibrator beads showed optimal stability at room temperature, which may be important in inter-laboratory comparisons. The calibrator beads are smaller than cells. It is therefore possible to mix the beads directly with the patient cells and analyze the P-H2AX signal separately from the beads and patient cells in the flow cytometer and correct for signal differences between days and antibody batches. Titration of the amount of phosphopeptide per bead to match the signal from cells is of great importance, as the beads would otherwise attenuate the P-H2AX signal in the cells by antibody depletion. A potential problem with the beads is that they do not present the antigen in a way that resembles the cellular structure in fixed cells. This might generate problems if calibrator beads are used to harmonize $\mathrm{P}-\mathrm{H} 2 \mathrm{AX}$ methods using different $\mathrm{P}-\mathrm{H} 2 \mathrm{AX}$ antibodies. For this reason, we also established controls based on
A

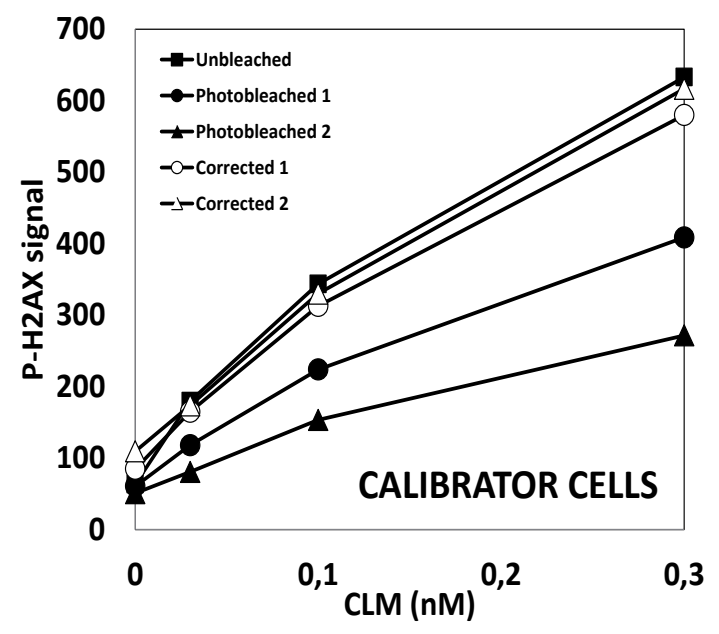

B

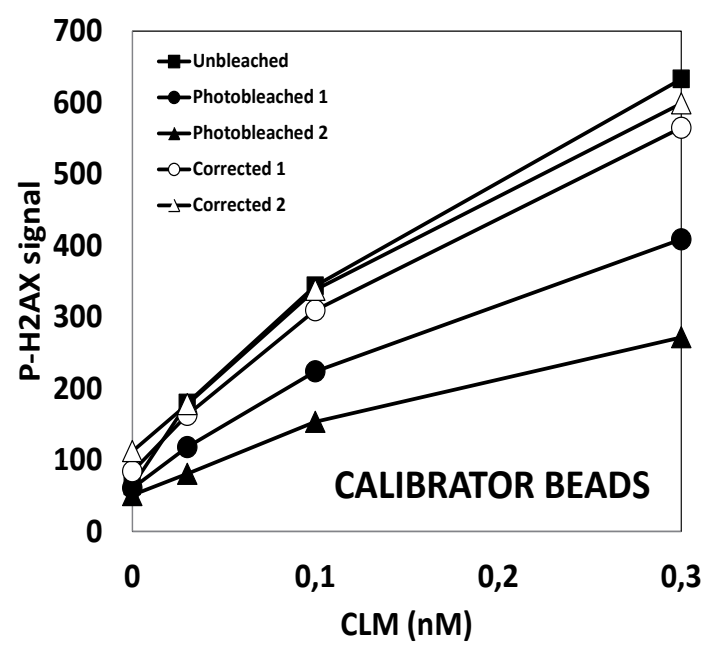

Fig. (3). Corrections of antibody-related differences in the $\mathbf{P}$ H2AX signal. Primary fibroblasts were treated with $0,0.03,0.1$ and $0.3 \mathrm{nM} \mathrm{CLM}$ for $30 \mathrm{~min}$ at $37^{\circ} \mathrm{C}$. Calibrator beads, calibrator cells and CLM-treated fibroblasts were stained with unbleached or two batches of differently photobleached FITC-labeled P-H2AX antibodies. The P-H2AX signal from calibrator cells (A) or calibrator beads (B) were used to correct the signal using the two photobleached antibody batches (Corrected 1 and 2). 
cells expressing P-H2AX. These cells will, however, be less amenable to large-scale production. In addition, the P-H2AX signal in fixed cells was not stable at room temperature, making them less suitable as inter-laboratory controls. The calibrator beads and calibrator cells performed equally well in correcting for differences in signal intensity among different antibody preparations and day-to-day variation. Together, these two calibrators can be used to assess the signal fluctuations due to sample handling, antibody batches, dayto-day variation and variation in the flow cytometer output.
There was a hyperbolic correlation between the amount of peptide on the beads and the FITC signal. This hyperbolic correlation was also observed for the calibrator cells with different amounts of P-H2AX signal. To be able to correct optimally for signal differences between days or different antibody batches we used calibration curves from a range of preparations of calibrator beads or calibrator cells with different signal intensities. This multi-point calibration approach to calibrate signals from non-linear methods is commonly used in clinical assays and is known to be reliable.

Table 3. Stability of Calibrator Cells

\begin{tabular}{|c|c|c|c|c|}
\hline $\begin{array}{c}\text { Storage } \\
\text { (days) }\end{array}$ & $\begin{array}{c}\text { MetOH } \\
\text { (\% of Calibrite signal) }\end{array}$ & $\begin{array}{c}\text { PFA, MetOH } \\
\text { (\% of Calibrite signal) }\end{array}$ & $\begin{array}{c}\text { EtOH } \\
\text { (\% of Calibrite signal) }\end{array}$ & $\begin{array}{c}\text { PFA, EtOH } \\
\text { (\% of Calibrite signal) }\end{array}$ \\
\hline \hline 3 & 462.7 & 358.1 & 555.5 & 381.2 \\
\hline 10 & 435.8 & 426.9 & 588.2 & 393.1 \\
\hline 40 & 489.8 & 394.9 & 559.4 & 427.9 \\
\hline
\end{tabular}
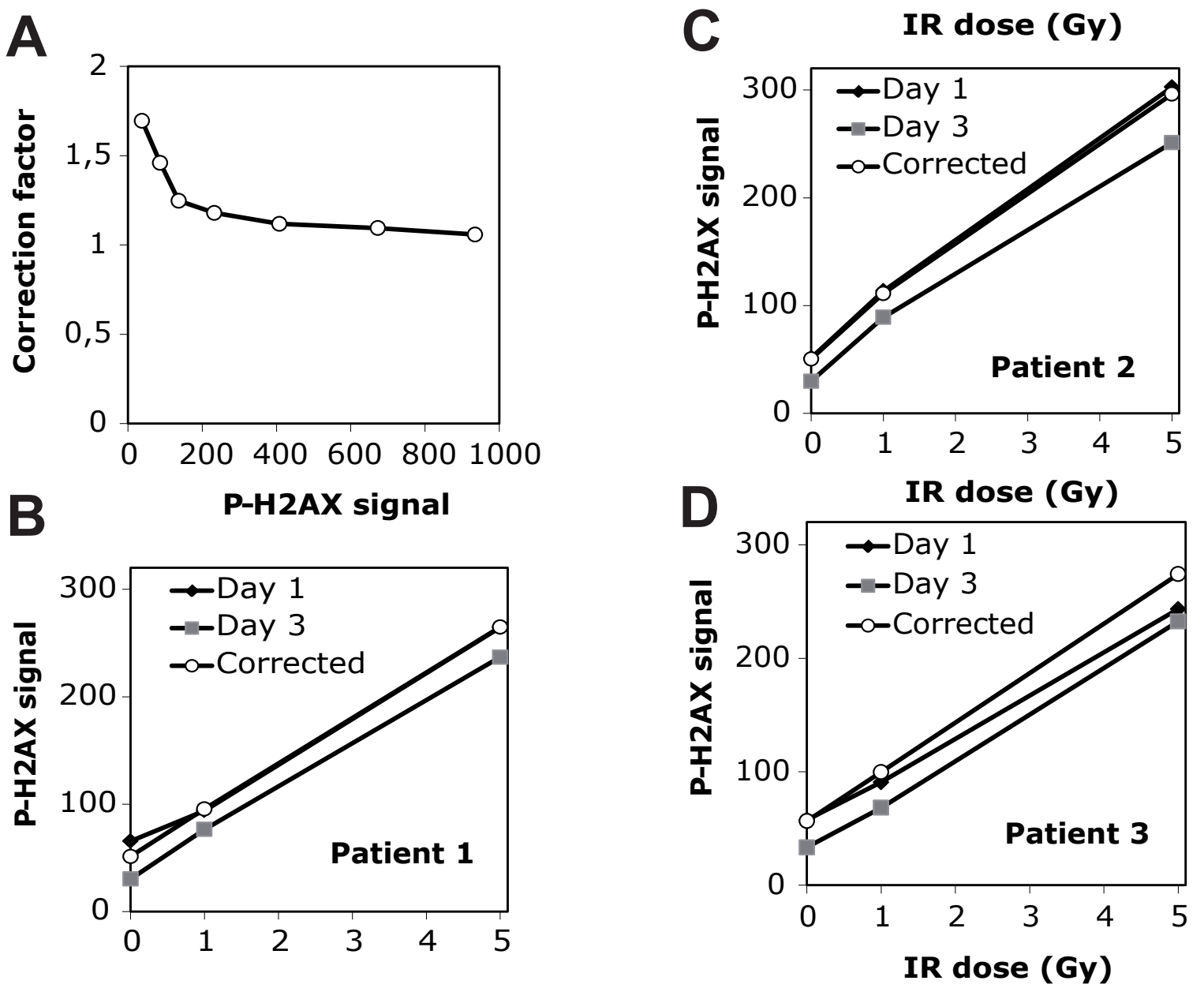

Fig. (4). Corrections of day-to-day variations in patient lymphocytes. Blood samples from three healthy individuals were collected and irradiated with 0,1 and 5 Gy. Patient lymphocytes and calibrator cells were stained and analyzed by flow cytometry. The same procedure was performed two days later and the resulting P-H2AX signals were corrected as described in the Materials and Methods section. A: Correction factor calculated as a difference between days 1 and 3 was plotted against the P-H2AX signals used to calculate the correction factors. B-D: P-H2AX signal on day 1 and 3 before and after correction in patients 1, 2, and 3. 
With the use of these calibrators it will now be possible to perform multicenter studies of the extent of correlation between side effects and tumor control using radiotherapy and chemotherapy and the P-H2AX signal in patient cells.

\section{CONFLICT OF INTEREST}

The authors confirm that this article content has no conflicts of interest.

\section{ACKNOWLEDGEMENTS}

This work was supported by the Swedish Cancer Society, the Swedish Research Council, the Swedish Pain Foundation (SSF), the Assar Gabrielsson Cancer Research Foundation, and by LUA/ALF Funding at the Sahlgrenska University Hospital.

\section{REFERENCES}

[1] Tounekti, O.; Kenani, A.; Foray, N.; Orlowski, S.; Mir, L.M. The ratio of single- to double-strand DNA breaks and their absolute values determine cell death pathway. Br. J. Cancer, 2001, 84(9), $1272-1279$.

[2] Rogakou, E.P.; Pilch, D.R.; Orr, A.H.; Ivanova, V.S.; Bonner, W.M. DNA Double-stranded Breaks Induce Histone H2AX Phosphorylation on Serine 139. J. Biol. Chem., 1998, 273(10), 58585868.

[3] Paull, T.T.; Rogakou, E.P.; Yamazaki, V.; Kirchgessner, C.U.; Gellert, M.; Bonner, W.M. A critical role for histone H2AX in recruitment of repair factors to nuclear foci after DNA damage. Curr. Biol., 2000, 10(15), 886-895.

[4] Ward, I.M.; Chen, J. Histone H2AX is phosphorylated in an ATRdependent manner in response to replicational stress. J. Biol. Chem., 2001, 276(51), 47759-47762.

[5] Burma, S.; Chen, B.P.; Murphy, M.; Kurimasa, A.; Chen, D.J. ATM Phosphorylates Histone H2AX in Response to DNA Doublestrand Breaks. J. Biol. Chem., 2002, 276, 42462-42467.
[6] Furuta T, Takemura H, Liao ZY, et al. Phosphorylation of histone $\mathrm{H} 2 \mathrm{AX}$ and activation of Mre11, Rad50, and Nbs1 in response to replication-dependent DNA double-strand breaks induced by mammalian DNA topoisomerase I cleavage complexes. J. Biol. Chem., 2003, 278(22), 20303-20312.

[7] Stiff, T.; O'Driscoll, M.; Rief, N.; Iwabuchi, K.; Löbrich, M.; Jeggo, P.A. ATM and DNA-PK function redundantly to phosphorylate $\mathrm{H} 2 \mathrm{AX}$ after exposure to ionizing radiation. Cancer Res., 2004, 64(7), 2390-2396.

[8] Ward, I.M.; Minn, K.; Chen, J. UV-induced ataxia-telangiectasiamutated and Rad3-related (ATR) activation requires replication stress. J. Biol. Chem., 2004, 279(11), 9677-9680.

[9] Sedelnikova, O.A.; Rogakou, E.P.; Panyutin, I.G.; Bonner, W.M. Quantitative detection of (125)IdU-induced DNA double-strand breaks with P-H2AX antibody. Radiat. Res., 2002, 158(4), 486492.

[10] Pilch, D.R.; Sedelnikova, O.A.; Redon, C.; Celeste, A.; Nussenzweig, A.; Bonner, W.M. Characteristics of P-H2AX foci at DNA double-strand breaks sites. Biochem. Cell Biol., 2003, 81(3), 123-129.

[11] Rothkamm, K.; Löbrich, M. Evidence for a lack of DNA doublestrand break repair in human cells exposed to very low x-ray doses Proc. Natl. Acad. Sci. USA, 2003, 100(9), 5057-5062.

[12] Ismail, I.H.; Wadhra, T.I, Hammarsten, O. An optimized method for detecting $\mathrm{P}-\mathrm{H} 2 \mathrm{AX}$ in blood cells reveals a significant interindividual variation in the $\mathrm{P}-\mathrm{H} 2 \mathrm{AX}$ response among humans. Nucleic Acids Res., 2007, 35(5), e36.

[13] Muslimovic, A.; Ismail, I.H.; Gao, Y.; Hammarsten, O. An optimized method for measurement of P-H2AX in blood mononuclear and cultured cells. Nat. Protoc., 2008, 3(7), 1187-1193.

[14] Andrievski, A.; Wilkins, R.C. The response of gamma-H2AX in human lymphocytes and lymphocytes subsets measured in whole blood cultures. Int. J. Radiat. Biol.,2009, 85, 369-376.

[15] Porcedda, P.; Turinetto, V.; Brusco, A. A rapid flow cytometry test based on histone $\mathrm{H} 2 \mathrm{AX}$ phosphorylation for the sensitive and specific diagnosis of ataxia telangiectasia. Cytometr. A., 2008, 73, 508516.

[16] Bourton, E.C.; Plowman, P.N.; Smith, D.; Arlett, C.F.; Parris, C.N. Prolonged expression of the gamma-H2AX DNA repair biomarker correlates with excess acute and chronic toxicity from radiotherapy treatment. Int. J. Cancer, 2011, 129(12), 2928-2934. 